\title{
Determinants of Wheat Consumption, Irrigated Agriculture, and Food Security Challenges in Egypt
}

\author{
LAL K. ALMAS ${ }^{1 *}$, MUHAMMAD USMAN ${ }^{2}$ \\ ${ }^{1 *}$ Regents Professor of Agricultural Business \& Economics, and Associate Dean, Paul Engler \\ College of Agriculture \& Natural Sciences, West Texas A\&M University, Canyon, Texas, USA \\ ${ }^{2}$ Visiting Research Scholar at Paul Engler College of Agriculture \& Natural Sciences, WTAMU \\ and Ph.D. Student, Department of Economics, Arid Agriculture University Rawalpindi, \\ PAKISTAN.
}

Abstract: Wheat is one of the most widely cultivated cereal crops and consumable staple food globally. Internal production efforts are essential to reduce the ever increasing gap between production and consumption of wheat in Egypt. The production-consumption gap can be reduced through advanced agriculture, innovative wheat varieties, land expansion, bio-saline agriculture, and other water management practices. This research study aims to investigate the determinants of wheat consumption in Egypt, find the price, income, and cross price demand elasticities of wheat. For empirical analysis, the annual time series data from 1961 through 2020 is collected from different sources. The data is analyzed through the Autoregressive Distributive Lag (ARDL) model to investigate the long-run demand determinants of wheat in Egypt. The estimated results indicate the presence of a long-term relationship among determinants of wheat consumption. The results of own price, GDP per capita, and population reveal that wheat is a necessity food. Similarly, the estimates of rice price, corn consumption, and barley consumption indicate that such commodities are substitutes for wheat in Egypt. Based on these estimates, it is suggested that the policy makers in the Egyptian government and all other stakeholders need to concentrate on a comprehensive policy for parallel consumption of wheat, rice, corn, and barley. It is also recommended that the Egyptian government must focus on exploring ways including bio-saline agriculture to increase domestic wheat production to reduce wheat imports, save valuable foreign exchange, and overcome some of the food security challenges in Egypt.

Key-Words: - Wheat Demand Determinants, Own Price Elasticity, Income Elasticity, Cross Price Elasticity, Wheat Production Gap, Food Security, Bio-saline Agriculture, Autoregressive Distributed Lag (ARDL) Model, Egypt.

Received: December 12, 2020. Revised: June 10, 2021. Accepted: June 24, 2021. Published: July 7, 2021.

\section{Introduction}

Economic theories provide the framework regarding demand analysis of any commodity. Wheat demand is dependent on its own price, per capita income, prices of related staple foods, and other control variables such as country population and inflation rate [1][2]. Demand for wheat is dependent on several direct and indirect factors; direct factors include wheat price, household income, and wheat supply, while indirect factors are prices of substitutions and complementary goods, country population, inflation, consumer taste, and preferences [3]
[4]. The positive income elasticity indicates that people's attitudes towards wheat demand increase with higher income level and vice versa [1]. Conversely, a country with lower per capita income demands more wheat because of poverty. Rising poverty and hunger index are fundamental challenges to ensure the food security globally [1].

Wheat is an essential dietary ingredient which is heavily subsidized by the Egyptian government. Through subsidy, the government provides cheaper wheat accessibility to the consumers and wheat support price to the 
producers. In Egypt, the demand for wheat is highly price-elastic [5], and wheat production is insufficient to meet the demand [6] [7] [8]. Consequently, to ensure food security and fulfill the domestic wheat demand Egyptian government relies heavily on imported wheat. The wheat subsidy, population pressure and lower domestic production are the reasons for high wheat import in Egypt [9][10] [11] .

Egypt is one of the largest wheat importer in the world [12] and imports over half of its total wheat consumption [13]. Egyptian wheat imports were declined during 2019-20 at 12.68 million tonnes from 13.3 million during a year before. The wheat import decreased due to a rise in domestic wheat production during 2019-20, wheat production increased from 8.77 to 8.9 million tonnes in 2019-2020, compared to 20182019 [14]. The aggregate domestic wheat consumption in Egypt rose from 20.3 million tonnes to 20.8 million tonnes during 2020-21, which is due to high population growth. Currently, Egypt's population is about 102 million people, with a growth rate of 1.94 percent, which is anticipated being double in 2078 [15]. Increase in predicted population will cause increase in wheat demand in Egypt. The rapidly growing population poses serious challenges to Egyptian food security. Currently, one-third of the Egyptian population is living below the poverty (spending less than $\$ 1.97$ per person per day), with the unemployment rate at 10 percent [15]. These socioeconomic indicators may even lead to worsen the food security challenges in Egypt.

In Egypt, the cultivated land is located near the Nile River, its connected branches, canals, and Nile deltas. The total cultivated land is only 4 percent of total land area. The agriculture landholding is very small, and 50 percent holding is less than 0.42 hectare which is about one Feddan. The small landholding allowed the agrarians to grow the staple food crops, particularly wheat, cereals, barley, maize, beans, lentils, fruits, and vegetables [17][18]. In China, wheat producing areas consume majority of their wheat produced locally [18]. Same situation is prevalent in Egypt, the locally produced wheat has consequently been consumed by rural consumers, which reveals that domestic production is not sufficient to sell to the government [19], which puts pressure on wheat imports. Moreover, the government price policy to achieving wheat autarky is costly and impudent for rural producers and consumers.

The endeavor of the Egyptian government for doubling the irrigated land till 2035 may be a way to increase and make Egypt self-sufficient in wheat production. But the modest population growth would make such efforts insufficient after 2040. Additionally, the increasing cultivable land to achieve wheat self-sufficiency is also an encouraging initiative. However, water supply remains a challenge for irrigation and sufficient wheat production [7] [8]. The government policies regarding cultivated land expansion and wheat self-sufficiency seems inadequate to fulfill the growing wheat requirement in Egypt. [17] described that with new crop varieties and technological innovation, the Egypt wheat output has increased by 6.7 million metric tonnes from 1961 to 2017. However, appropriate land utilization, innovative technology, and suitable policies can expand the wheat production, but still may not be sufficient to cope domestic demand for wheat [5]. Maintaining the irrigated land given water availability constraints and climatic vulnerability are fundamental challenges for Egypt's wheat production in the future [13]. [20] investigated the effect of injected saline water on wheat productivity and found that drip irrigation has significant impact on wheat straw and grain yield with 7.11 and 6.12 percent increase, respectively by using saline water irrigation. Through adoption of innovation and government agriculture policies may be helpful to reduce the wheat imports to some extent.

With the recent trend and technological innovation in agriculture, the Egyptian economy can overcome its wheat imports through increasing domestic wheat production [19]. Despite this, the wheat output can be enhanced through innovative technology adoption, water management, and cultivated land expansion. However, climatic vulnerability may diminish future agriculture production in Egypt. The water, agricultural land, and severe climate are limiting factors affecting wheat production. Rise in the $\mathrm{CO}_{2}$ emission and temperature produces a negative impact on agriculture productivity. The innovative wheat varieties are influential factors 
to enhance domestic wheat production [18]. The adoption of new wheat varieties is remedial to reduce 5.3 percent to 8.3 percent of wheat imports in Egypt [21]. [22] argued that bioethanol is the essential raw material for high yield wheat production to fulfill the domestic wheat demand. [17] highlights that improvised wheat varieties (wheat breeding), irrigation innovation, new cultivation techniques contribute a 97 percent increase in wheat production and a 1.5 percent wheat yield increase due to cultivation land expansion. Additionally, [23] argued that the government's long-term policies for small farmers were adequately good to enhance agriculture growth. The new wheat varieties are rust-resistant, irrigation deficit, abiotic stress, which leads to high yields. It is emphasize that wheat farmers must focus on new cultivation techniques, fertilizers use, hybrid seed varieties, and water management [18]. Agricultural sustainability depends on the technology adoption strategies with government policies towards climatic change, technological and irrigation innovation, adoption of bio saline water to protect and facilitate the agrarians [17] [24].

The wheat products have high-income elasticity over rice and other edible commodities. [25] estimated that the cross and own-price elasticities of wheat and concluded that soft wheat is less price-sensitive than hard wheat. However, wheat cross-price elasticities highlighted that the soft, hard-red and spring wheat varieties are economic substitutes. The lower domestic wheat prices exert upward pressure on wheat imports [8] [9] [26]. The wheat prices speculated by the lower-income consumers cause the people to buy wheat at 8.92 percent higher prices [27]. [28] found that longrun income elasticity has a significant determinant of wheat demand while the price elasticity is a major short-run determinant of wheat consumption. The wheat price has a notable impact on supply but does not affect wheat demand [29]. [30] explored that Russia is competing in wheat exports to Egypt and Turkey, while Russia utilizes the market power in the Turkish wheat market with an estimated 13.5 percent mark-up. The expanding factors of wheat consumption are wheat quality and safely processed wheat products [31].
In addition, [5] found the negative and robust wheat demand shock in 2011, which transformed from political instability. The urban wheat demand is prolonged than rural, which is satisfied through imported wheat. Further, the temporary delay in wheat import raised the vulnerability and food insecurity in Egypt. Similarly, [32] illustrated that the demand for wheat in urban areas increased over a rural area in Bangladesh. In Africa, per capita income, population, and women labor force are essential drivers for rising wheat demand [2][33] investigated that wheat cultivated area during summer and winter is decreasing, while the marginal wheat consumption is increasing in South Africa, thus put pressure on wheat imports.

Meanwhile, the demand for wheat increased due to population growth, which gradually increases the production and consumption gap in wheat availability and accessibility. The increasing wheat consumption and production gap exert pressure on wheat imports in Egypt. [34] reported that the production, consumption, and imports are grave factors for food security, such as barley, wheat, and poultry perform a vital role in food accessibility. The projected population growth rate is faster than the domestic wheat production in Egypt. So, [13] demonstrated that Egyptian population growth is higher than moderate level, which exerts pressure on wheat consumption, due to which demand for wheat in Egypt is rising. Similarly, [35] demonstrated that GDP per capita, imported wheat, and sugar cane are complements for wheat while domestic wheat production deviates from the imported wheat. The Arab countries can reduce the price vulnerability and food insecurity problem by enhancing domestic food production through rural development. In this scenario, Arab countries should promote agricultural education, access to family planning, and domestic safety nets for food security, moreover, reduce the market volatility through the effective supply chain and food price volatility [36].

From the existing literature, this study found that the present studies focused on the availability, supply and production of wheat in Egypt [13] [17] [21] [37], while the wheat demand with alternative consumption shift was 
missing in the literature. The fundamental need of this study is to highlight the demand side challenges of wheat in Egypt. For instance, this study tried to answer the following questions, those are not properly addressed in existing literature. What alternative commodities are available for wheat consumption in Egypt? What demographic and economic drivers are raising the wheat demand in Egypt? What fundamental food security challenges are faced by Egyptian population and how government can overcome these challenges through suitable policy practices? What are the economic factors affecting wheat consumption? Does the imported wheat have a significant impact on wheat consumption? Does the population growth affect wheat consumption? What role of inflation is playing in wheat demand and food insecurity in Egypt? Based on the knowledge gap in wheat demand, this study has the following objectives:

1. To evaluate the determinants of wheat consumption in Egypt with substitute shift of wheat consumption.

2. To reduce the wheat import through alternative food consumption and stabilize the food security.

3. To quantify the demand for wheat in Egypt and estimate the long and short-run own price, income, and cross-price demand elasticities of wheat in Egypt.

This study also investigates the impact of wheat import, inflation, and the population size on wheat consumption. This study also forecasts the demand for wheat with respect to increasing population. This study provides the policy implications for the Egyptian economy to meet domestic wheat demand and avoid from food insecurity challenges.

\section{Research Methodology}

The Keynesian economic theory suggested that the country's aggregate domestic consumption is dependent on the aggregate level of per capita income. The aggregate demand function highlights the relationship between own price, income and complementary and substitute goods in the economy. Economic theory represents that the wheat demand is dependent on wheat price, consumers income and prices of substitutes [1], as much a commodity has more substitutes the quantity demanded of that commodity will be less elastic. So, the functional relationship of demand theory can be expressed as follows:

$$
Q d_{x}=f\left(P_{x}, Y_{t}, P_{s}, P_{c}\right)
$$

The functional relation indicates that $\mathrm{Qd}_{\mathrm{x}}$ is quantity demanded for commodity $\mathrm{X}, \mathrm{P}_{\mathrm{x}}$ is the price of commodity $\mathrm{X}, \mathrm{Y}_{\mathrm{t}}$ represents the level of income at given time, $\mathrm{P}_{\mathrm{s}}$ represents the price of substitution goods, $\mathrm{P}_{\mathrm{c}}$ is a price of complementary goods. Macroeconomic theory highlights that wheat consumption is dependent on its own price, consumer income, prices of related staple foods, and control variables such as population size and inflation rate [2]. Additionally, demand for Wheat is dependent on several direct and indirect factors; direct factors include wheat price, household income, and wheat supply, while indirect factors are prices of substitutions and complementary goods, country population, inflation, consumer taste, and preferences [1] [3] [4]. Therefore, the country's demand for wheat is dependent on wheat price, prices of related staple foods (like Rice, Corn, Barley, Sorghum, etc.), population, per capita GDP, and inflation rate. To identify the wheat demand determinant and food security challenges in Egypt, we adopted the econometric model in a double log form to quantify the elasticities.

By adding the intercept, slope coefficient and error term, econometrically we express the aggregate demand function as followings:

$$
Q d_{x}=\alpha_{0}+\alpha_{1} P_{x}+\alpha_{2} Y_{t}+\alpha_{3} P_{s}+\alpha_{4} P_{c}+\varepsilon
$$

We modify the generalized aggregate demand equation according to the theoretical background and availability of data related to essential wheat demand determinants. The dependency relationship of Wheat Consumption (WC) was specified with substitutable staple foods like Rice Prices (RP), Corn Consumption (CC), and Barley Consumption (BC). Due to unavailability of prices data of both corn and barley, we utilized the consumption as substitute 
variable. The other important variables that effect the demand for wheat are Gross Domestic Product Per Capita (GDPP), Population (POP), Wheat Imports (WI), and Consumer Price Index (CPI). The reason for introducing the WI variable in the model is that the Egyptian economy imports more than 50 percent of wheat to fulfill its demand [13]. Econometrically the modified form of wheat aggregate demand equation as follows:

$$
\begin{aligned}
& W C_{t}=\alpha_{0}+\alpha_{1} W P_{t}+\alpha_{2} R P_{t}+\alpha_{3} C C_{t}+ \\
& \alpha_{4} B C_{t}+\alpha_{5} G D P P_{t}+\alpha_{6} P O P_{t}+\alpha_{7} W I_{t}+ \\
& \alpha_{8} C P I_{t}+\varepsilon_{t}
\end{aligned}
$$

We took the log of both sides to measure the elasticities both in short and long run dynamic of wheat consumption in Egypt. The linear doublelog model has an important feature, through which we measure coefficient elasticities that represent the percentage change in dependent variables to one percentage change in the independent variable [38]. By taking the logarithmic of both sides the final estimated model was following:

$$
\begin{aligned}
& L n W C_{t}=\alpha_{0}+\alpha_{1} L n W P_{t}+\alpha_{2} L n R P_{t}+ \\
& \alpha_{3} L n C C_{t}+\alpha_{4} L n B C_{t}+\alpha_{5} L n G D P P_{t}+ \\
& \alpha_{6} L_{n P O P}+\alpha_{7} L n W I_{t}+\alpha_{8} L n C P I_{t}+\varepsilon_{t}
\end{aligned}
$$

In equation 3, all estimated variables are in logarithmic form, and the dependent variable is $\mathrm{WC}_{\mathrm{t}}$, while independent variables are $\mathrm{WP}_{t}, \mathrm{RP}_{\mathrm{t}}$, $\mathrm{CC}_{\mathrm{t}}, \mathrm{BC}_{\mathrm{t}}, \mathrm{GDPP}_{\mathrm{t}}, \mathrm{POP}_{\mathrm{t}}, \mathrm{WI}_{\mathrm{t}}$, and $\mathrm{CPI}_{\mathrm{t}}$. Description of all variables is given in Table 1. The $\alpha_{0}$ is intercept and $\alpha_{1}$ to $\alpha_{8}$ are representing the slope coefficients, ' $t$ ' representing the time period and $\varepsilon_{\mathrm{t}}$ representing the residual term.

Table1. Variables and Description

\begin{tabular}{llll}
\hline Abbreviations & Description of Variables & Measuring Units & Data Source \\
\hline $\mathrm{WC}_{\mathrm{t}}$ & Wheat Consumption & Metric Tonnes & $\begin{array}{l}\text { Food and Agriculture Organization } \\
\text { (FAO), Index Mundi }\end{array}$ \\
$\mathrm{GDPP}_{\mathrm{t}}$ & GDP Per Capita & UD Dollars & World Development Indicators (WDI) \\
$\mathrm{WP}_{\mathrm{t}}$ & Wheat Prices & US Dollars & FAO, Index Mundi, Satatista \\
$\mathrm{RP}_{\mathrm{t}}$ & Rice Price & US Dollars & FAO, Index Mundi, Statista \\
$\mathrm{CC}$ & Corn Consumption & Metric Tonnes & FAO, Index Mundi \\
$\mathrm{BC}_{\mathrm{t}}$ & Barley Consumption & Metric Tonnes & FAO, Index Mundi \\
$\mathrm{POP}_{\mathrm{t}}$ & Total Population & Millions & WDI \\
$\mathrm{WI}_{\mathrm{t}}$ & Wheat Imports & Metric Tonnes & FAO, Index Mundi, UN-Comtrade \\
$\mathrm{CPI}$ & Consumer Price Index & Index & WDI \\
\hline
\end{tabular}

Source: Authors own's

\subsection{Data and Data Sources}

The aim of this research is to explore the wheat demand determinants in Egypt. This study also investigates the impact of wheat price, per capita income, prices of substitutions goods, inflation rate, wheat imports and the population size on wheat consumption. For analytical analysis, this study collected the annual time series data covering from 1961 to 2020 period, which is collected from different secondary sources. The secondary source data is collected from World Development Indicators (WDI), Food and Agriculture Organization (FAO), United States Department of Agriculture (USDA), Index Mundi, UN-Comtrade, and Statista.

\subsection{Estimation Techniques}

This study adopts the linear double logarithmic model to investigate the wheat demand determinants in Egypt. The linear double-log model has an important feature, through which we measure coefficients elasticities to express short and long term dependency relationship [38]. To measure the short- and long-term elasticities of wheat consumption in Egypt, the Autoregressive Distributed Lag (ARDL) model is adopted. In the estimated model, different influential wheat consumption variables are opted to find the income, cross-price, and own price elasticities with control variables such as population, consumer price index, and wheat import. The ARDL bound test-based model was developed 
by [39]. The ARDL model has the efficiency to work with short and long-run coefficients simultaneously and applicable on both level and first-order stationary variables [24]. We analyzed the wheat demand determinants through complementary analysis and forecasted the wheat consumption, population size, wheat production and gap between consumption and production.

\section{Results and Discussion}

The determinants of wheat consumption and food security issues in Egypt were analyzed through demand analysis with the help of ARDL model. For empirical results, initially, we applied a unit root test to find the deterministic trend. The lag length criteria are employed to determine the appropriate lag. After lag selection we applied the ARDL bound test for cointegration relationship. The dependency relationship is carried by taking wheat consumption $\left(\mathrm{WC}_{\mathrm{t}}\right)$ as dependent variable and independent variables are rice price $\left(\mathrm{RP}_{\mathrm{t}}\right)$, barley consumption $\left(\mathrm{BC}_{\mathrm{t}}\right)$, corn consumption $\left(\mathrm{CC}_{\mathrm{t}}\right)$, per capita GDP $\left(\mathrm{GDPP}_{\mathrm{t}}\right)$, total population $\left(\mathrm{POP}_{\mathrm{t}}\right)$, wheat imports $\left(\mathrm{WI}_{\mathrm{t}}\right)$, and consumer price index $\left(\mathrm{CPI}_{\mathrm{t}}\right)$.

\subsection{Stationarity Test Results}

The estimates of the Phillips-Perron (PP) and Augmented Dickey-Fuller (ADF) tests are given in Table 2. The results of both PP and ADF tests indicate that the $\mathrm{WC}_{\mathrm{t}}, \mathrm{WP}_{\mathrm{t}}, \mathrm{CC}_{\mathrm{t}}, \mathrm{GDPP}_{\mathrm{t}}, \mathrm{POP}_{\mathrm{t}}$, $\mathrm{WI}_{t}$, and $\mathrm{CPI}_{t}$ are the stationary at first difference, however $\mathrm{RP}_{t}$ and $\mathrm{BC}_{t}$ are level stationery. Therefore, the variables in the estimated model are a mixture of both level and first-order integration, which leads us to apply the ARDL model for the long and short-run dynamics.

Table 2. Stationarity Test Results

\begin{tabular}{lllll}
\hline Variables & \multicolumn{2}{c}{ PP Test } & ADF Test \\
\hline & Level & First Difference & Level & First Difference \\
$\mathrm{WC}_{\mathrm{t}}$ & 1.0092 & -7.6955 & 1.0092 & -7.6863 \\
& $(0.9962)$ & $(0.0000)^{*}$ & $(0.9962)$ & $(0.0000)^{*}$ \\
$\mathrm{WP}_{\mathrm{t}}$ & -0.3052 & -7.5700 & 0.2315 & -7.5615 \\
& $(0.5715)$ & $(0.0000)^{*}$ & $(0.7499)$ & $(0.0000)^{*}$ \\
$\mathrm{RP}_{\mathrm{t}}$ & -6.8238 & -41.8889 & -6.4770 & -8.3367 \\
& $(0.0000)^{*}$ & $(0.0001)$ & $(0.0000)^{*}$ & $(0.0000)$ \\
$\mathrm{BC}_{\mathrm{t}}$ & -4.9476 & -10.5318 & -4.9473 & -9.1432 \\
& $(0.0009)^{*}$ & $(0.0000)$ & $(0.0009)^{*}$ & $(0.0000)$ \\
$\mathrm{CC}_{\mathrm{t}}$ & -1.7122 & -10.3668 & -1.5898 & -11.075 \\
& $(0.7334)$ & $(0.0000)^{*}$ & $(0.7850)$ & $(0.0000)^{*}$ \\
$\mathrm{GDPP}_{\mathrm{t}}$ & 1.5553 & -6.8548 & 1.1756 & -3.9525 \\
& $(0.9993)$ & $(0.0000)^{*}$ & $(0.9977)$ & $(0.0032)^{*}$ \\
$\mathrm{CPI}_{\mathrm{t}}$ & -1.188086 & -6.8786 & -0.0483 & -4.0033 \\
& $(0.9037)$ & $(0.0000)^{*}$ & $(0.9497)$ & $(0.0027)^{*}$ \\
$\mathrm{POP}_{\mathrm{t}}$ & -1.6887 & -4.7436 & -1.4237 & -3.8778 \\
$\mathrm{WI}_{\mathrm{t}}$ & $(0.7439)$ & $(0.0003)^{*}$ & $(0.1422)$ & $(0.0198)^{*}$ \\
& -0.4538 & -9.4304 & -0.1093 & -9.4304 \\
& $(0.8923)$ & $(0.0000)^{*}$ & $(0.9431)$ & $(0.0000)^{*}$ \\
\hline
\end{tabular}

* Indicates the level of stationary of respected variable. Source: Authors Calculation

\subsection{Lag Length Criteria}

Time series data have trending behavior and current observation effects from previous or lag period value. Fluctuation in time series data creates the problem of autocorrelation, which can be removed through appropriate lag selection. Lag selection process in timeseries data is utilized to convert the given variable into growth form, which is also helpful in 
autocorrelation elimination. [40] argued that lag differencing and Cochrane-Orcutt methods are suitable for autocorrelation removal. For optimal lag length, different estimation techniques are applied, such as Schwarz Bayesian Criterion (SBC), Hannan Quinn Criterion (HQC), Akaike Information Criterion (AIC), etc. The AIC is more efficient over the HAQ and SBC, while HAQ and SBC provide consistent results over AIC. The estimated results of lag length criteria are given in Table 3 (See Appendix A). For estimation, we adopt the AIC approach to select the optimal lag and the ARDL model is estimated by using computer package E-Views [41].

\subsection{Cointegration and Long Run Coefficient}

The ARDL bound test is applied to examine the long run cointegration relationship among given variables (see equation 3). The null hypothesis of the bound test is "no long-run relationship" among estimated variables. The estimated values are presented in Table 4 (See Appendix B). The computed value of the Bound test is greater than the upper-bound, which suggests the rejection of the null hypothesis of no long-run relationship. Consequently, the estimated results show a longrun relationship between wheat consumption and its determinant as given in the estimated model. This shows that cointegration relationship exists among estimated variables. The bound statistics indicates that the $\mathrm{WC}_{\mathrm{t}}, \mathrm{WP}_{\mathrm{t}}, \mathrm{RP}_{\mathrm{t}}, \mathrm{CC}_{\mathrm{t}}, \mathrm{BS}_{\mathrm{t}}$, $\mathrm{GDPP}_{t}, \mathrm{WI}_{\mathrm{t}}$ and $\mathrm{CPI}_{t}$ has long-run association and anticipated results are justifiable for longterm policy suggestion. The estimated results of the long-run coefficients are given in Table 5. The wheat consumption in Egypt is dependent variable and explanatory variables are intended to capture the demographic and economic drivers in rising wheat demand in Egypt. The intercept value has a significantly negative impact on wheat consumption in Egypt. The intercept value is -10.78 which is significant at one percent level. The intercept value shows that keeping the independent variables fixed the exogenous variable affects the wheat consumption negatively. The exogenous factors may include protein consumption, meats, other cereals, fruit and vegetable consumption, etc.

The estimated results of GDPP $\mathrm{t}_{\mathrm{t}}$ show a positive and significant impact on wheat consumption. The coefficient value of GDPP is 0.1135 and significant at one percent level. The coefficient value determines that a one percent increase in Egyptian per capita $\mathrm{GDPP}_{\mathrm{t}}$ raises wheat consumption by 11 percent, ceteris paribus. The calculated value of $\mathrm{GDPP}_{\mathrm{t}}$ highlights that wheat demand is income elastic, and people are willing to buy more wheat with higher $\mathrm{GDPP}_{\mathrm{t}}$ and considered wheat as necessity food [2]. The high poverty level in Egypt is a reason for higher wheat demand with incremental $\mathrm{GDPP}_{\mathrm{t}}$, as the first priority of poor people is to spend on food to survive, which anticipates more spending on necessity commodities. The estimated results are inconsistent with [42], who confirmed the negative income elasticity of demand for wheat and argued that consumers in Iran considered wheat as inferior good with increasing income.

The coefficient value of $\mathrm{WP}_{t}$ is negative and significant. The estimated value of $\mathrm{WP}_{t}$ indicates that the law of demand holds in the case of wheat consumption in Egypt. The law of demand highlights that as the wheat prices going down people are willing to demand more wheat quantity. So, as the wheat prices going down, the people are willing to spend more wheat demand [1] The one percent reduction in wheat price leads to heighten the wheat consumption by 15 percent in Egypt. The demand for wheat consumption in Egypt is more price elastic, which indicates that wheat is a necessity commodity in Egypt. The results are in line with [2] findings who argued that world wheat prices are not essential to determine the domestic wheat consumption; however, domestic wheat prices affect the $\mathrm{WC}_{\mathrm{t}}$. Similarly, the wheat price has a significant impact on supply but does not affect wheat demand [29]. In contrast, [42] found that the wheat is Giffen good, and the law of demand does not hold in wheat demand.

Globally numerous countries consume rice as complimentary food, while other countries consume rice as a substitute for wheat. We include the $\mathrm{RP}_{\mathrm{t}}$ as the independent variable to examine the relationship between rice and wheat in Egypt. The coefficient value $\mathrm{RP}_{t}$ exhibits a negative and significant impact on wheat consumption. The calculated value of $\mathrm{RP}_{t}$ is 0.053 which is significant at 6 percent level. As the $\mathrm{RP}_{\mathrm{t}}$ decline, Egyptian people are willing to 
buy more rice by substituting wheat consumption. The estimated value of $\mathrm{RP}_{t}$ shows that rice is less-elastic substitutions of wheat consumption. The results validate that rice is consumed as a substitute for wheat in Egypt in long run [4]. The results validate that rice is consumed as a substitute for wheat in Egypt in long run. The coefficient value shows that a one percent reduction in $R P_{t}$ reduces wheat consumption by 5.3 percent, which indicates that the Egyptian government comprehensively focuses on a holistic policy for food security especially, the demand for wheat and rice. The estimates are in line with the results of [43], who argued that rice is a substitute commodity for wheat and has the potential to reduce wheat import.

The results of barley consumption $\left(\mathrm{BC}_{\mathrm{t}}\right)$ have a negative and significant impact on $\mathrm{WC}_{t}$ in Egypt. The estimated value of $\mathrm{BC}_{\mathrm{t}}$ is -0.053 , which is significant at 5 percent. The cross-price elasticity of $\mathrm{BC}_{\mathrm{t}}$ is -0.05 , which indicates both barley and wheat are consumed as a substitute in Egypt in long run. The estimated value of $\mathrm{BC}_{t}$ concludes that barley is less- elastic substitute with wheat consumption, which indicates that people are willing to buy more barley by substituting the wheat with less replaceability. The results are consistent with the findings of [42] who found that the wheat is Giffen good; however, the barley is a suitable substitute for wheat consumption. The coefficient value of corn consumption $\left(\mathrm{CC}_{\mathrm{t}}\right)$ has a negative and significant relationship with wheat consumption. The calculated value of $\mathrm{CC}_{t}$ is -0.19 and significant at one percent level. The value of $\mathrm{CC}_{\mathrm{t}}$ shows that corn is less- elastic substitute with wheat consumption bhut has higher substitutability than rice and barley in Egypt. The estimated value highlights that a one percent increase in $\mathrm{CC}_{t}$ leads to reduce the $\mathrm{WC}_{t}$ by 19 percent and vice versa; this indicates that wheat and corn commodities are consumed as substitutes in long run. Consistently, [44] argued that wheat flour has substitution with corn flour, and the addition of fruits improve the bread contents and quality.

The estimated coefficient of total population $\left(\mathrm{POP}_{\mathrm{t}}\right)$ has economically and statistically significant impact on $\mathrm{WC}_{t}$ in Egypt. The $\mathrm{POP}_{t}$ coefficient is significant at a one percent level with an elasticity of 0.16 . Therefore, this indicates that a one percent population raises in Egypt was directed to increase the wheat demand by 16 percent, ceteris paribus. Population size has elastic wheat demand, which directly affect the wheat availability at national level [3]. The increasing population puts pressure on wheat consumption, and people are willing to consume more wheat, it is projected that forecasted population and raising wheat demand creates food vulnerability problems in Egypt. In Egypt, to ensure food security and feed the larger population, a comprehensive wheat production policy, substitute consumption, and wheat import policy is required. Besides, [29] and [45] established that the population size seems an essential determinant of wheat demand.

The slope coefficient of wheat import $\left(\mathrm{WI}_{t}\right)$ has a positive and significant influence on wheat consumption. The estimated value of $\mathrm{WI}_{t}$ is 0.053 which is significant at one percent level. The result highlights that a one percent increase in wheat $\mathrm{WI}_{\mathrm{t}}$ leads to an increase in the $\mathrm{WC}_{\mathrm{t}}$ by 5.3 percent. The coefficient of $\mathrm{WI}_{t}$ describes the deficiency of domestic wheat production and highly reliant on $\mathrm{WI}_{\mathrm{t}}$. The estimates are consistent with the findings of [5], who found that the temporary obstruction in wheat import raised the vulnerability and food insecurity in Egypt. In contradiction, [42] found that wheat imports do not influence internal prices, and wheat imports can be reduced through domestic production and consumption shift. Consumer Price Index $\left(\mathrm{CPI}_{t}\right)$ is an essential element that affects the consumer basket directly. The estimated value of $\mathrm{CPI}_{t}$ is negative and significant, which indicates that an increase in $\mathrm{CPI}_{t}$ leads the consumers to cut the wheat demand. The coefficient value shows one percent increase in $\mathrm{CPI}_{t}$ will reduce the $\mathrm{WC}_{t}$ by 14 percent in Egypt. The estimated results are consistent with the findings of [46], who argued that food price produced a negative impact on demand for wheat, and production policies are remedial to enhance supply and control food inflation. 
Table 5. Long Run Coefficients

\begin{tabular}{lll}
\hline Variables & Coefficient & Prob. \\
\hline Constant & -10.7859 & $0.0003^{* * *}$ \\
LWP $_{\mathbf{t}}$ & -0.1577 & $0.0126^{* *}$ \\
$\mathrm{LRP}_{\mathbf{t}}$ & 0.0530 & $0.0581^{*}$ \\
$\mathrm{LBC}_{\mathbf{t}}$ & -0.0531 & $0.0576^{*}$ \\
$\mathrm{LCC}_{\mathbf{t}}$ & -0.1927 & $0.0000^{* * *}$ \\
$\mathrm{LGDPP}_{\mathbf{t}}$ & 0.1135 & $0.0039 * * *$ \\
$\mathrm{LPOP}_{\mathbf{t}}$ & 0.1620 & $0.0007 * * *$ \\
$\mathrm{LWI}_{\mathbf{t}}$ & 0.0531 & $0.0000^{* * *}$ \\
LCPI $_{\mathbf{t}}$ & -0.1425 & $0.0035^{* *}$ \\
$*, * *, * *$ indicates the 10, 5 and 1 percent \\
\multicolumn{2}{l}{ significance level, respectively. } \\
\hline \multicolumn{2}{l}{ Source: Authors Calculation }
\end{tabular}

Source: Authors Calculation

\subsection{Discussion on Short Run Coefficient}

The estimated results of short run elasticities are presented in Table 6, with speed of adjustment coefficient. The $\mathrm{WC}_{\mathrm{t}}$ lag coefficient value has a positive and significant impact on the current $\mathrm{WC}_{\mathrm{t}}$. The consumer's previous period wheat consumption is keen to consume wheat in the current era. The short-run coefficient of $\mathrm{WP}_{\mathrm{t}}$ shows a negative and significant impact on $\mathrm{WC}_{t}$, which reveals that wheat is necessity commodity, and consumers are willing to buy more wheat at lower price. The lag coefficient value of $\mathrm{WP}_{\mathrm{t}}$ has a significantly negative impact on current period $\mathrm{WC}_{\mathrm{t}}$, which determines that the previous period $\mathrm{WP}_{t}$ affects the current wheat demand negatively. The results are in line with [2] findings, who argued that world wheat prices are not essential to determine the domestic wheat consumption; however, domestic wheat prices affect the $\mathrm{WC}_{\mathrm{t}}$. Therefore, it is evident that in the short run wheat is a normal good and consumers are willing to buy more wheat at lower prices.

Short-run estimated value of $\mathrm{RP}_{t}$ has a negative but insignificant impact on $\mathrm{WC}_{t}$ in Egypt, while lag coefficients of $\mathrm{RP}_{t}$ have a significantly negative influence on the current $\mathrm{WC}_{\mathrm{t}}$. This indicates that the lower previous period $\mathrm{RP}_{\mathrm{t}}$ reduce the $\mathrm{WC}_{\mathrm{t}}$ in the current period. Consistently, [43] argued that rice is a substitute commodity for wheat and has the potential to reduce wheat import. In the short run, Egyptian people are also consumed rice as the complimentary food for wheat. The short-run coefficient value of $\mathrm{BC}_{t}$ shows the same behavior as long-run estimates. Egyptian people utilized barley as a substitute for wheat consumption even though the barley has small consumption rate. However, the lag coefficient of $\mathrm{BC}_{\mathrm{t}}$ has a positive and significant impact on $\mathrm{WC}_{\mathrm{t}}$ therefore, in Egypt barley is also consumed as a complement of wheat. The results are consistent with the findings of [42] found the wheat is Giffen good; however, the barley is a suitable substitute for wheat consumption.

The $\mathrm{CC}_{\mathrm{t}}$ slope coefficient both in the shortrun and lag period have a significant and positive relationship with the current $\mathrm{WC}_{\mathrm{t}}$. The $\mathrm{CC}_{\mathrm{t}}$ coefficient value indicates that in the shortrun people consume corn as complementary good with wheat. Consistently, [44] argued that wheat flour has substitution with corn flour. The coefficient value of short-run GDPP $\mathrm{H}_{\mathrm{t}}$ behaves the same as the long-run. The coefficient value of first-period lag $\mathrm{GDPP}_{t}$ has an insignificant impact on the current $\mathrm{WC}_{\mathrm{t}}$ in Egypt. While the second-period lag harms $\mathrm{WC}_{\mathrm{t}}$, so if the people have a more previous income, they spend less on current wheat consumption. The estimated results are inconsistent with [42], who confirmed the negative income elasticity of demand for wheat and argued that consumers in Iran considered wheat as inferior good with increasing income. The positive income elasticity indicates that people's attitudes change towards wheat positively with increasing income. People are willing to buy more with higher income; this reveals that the Egyptian population has lower per capita income and facing poverty and hunger challenges [1].

The short-run coefficient of total $\mathrm{POP}_{t}$ has a similar effect on wheat consumption as appeared in the long run. Steadily, [29] and [45] established that the population size seems an essential determinant of wheat demand. The short-run estimate of $\mathrm{WI}_{t}$ has a similar impact on $\mathrm{WC}_{\mathrm{t}}$ as in the long run, while in the lag period, $\mathrm{WI}_{t}$ has a negative and significant impact on the current $\mathrm{WC}_{\mathrm{t}}$. Therefore, this indicates that the WI imported previously reduces the current $\mathrm{WC}_{\mathrm{t}}$. The estimated coefficients are consistent with the findings of [5], who found that the temporary obstruction in wheat import raised the vulnerability and food insecurity in Egypt. The coefficient value of short-run $\mathrm{CPI}_{t}$ has a negative and significant impact on $\mathrm{WC}_{t}$ parallel to the 
long-run coefficient. The estimated results are consistent with the findings of [46], who argued that food price produced a negative impact on demand for wheat, and production policies are remedial to enhance supply and control food inflation.

The cointegration coefficient measured the speed of adjustment. If any instability occurs in wheat consumption, the Error Correction Model (ECM) coefficient highlights the recovery (convergence) period. The negative and significant coefficient of ECM (-1) shows the existence of a long-run cointegration relationship among given variables, and the model has convergent behavior. The ECM (-1) value is -1.64 , which is significant at one percent level, this indicates that our estimated model has high speed of adjustment [24]. The coefficient value indicates that if there is any disequilibrium in wheat consumption, the speed of adjustment coefficient is remarkably high (1.64). The disequilibrium in the $\mathrm{WC}_{\mathrm{t}}$ of Egypt is recovered within a year or even in 8 months.

Table 6. Short Run Coefficients and Cointegration Form

\begin{tabular}{lll}
\hline Variable & Coefficient & Prob. \\
\hline $\mathrm{D}\left(\mathrm{LWC}(-1)_{\mathbf{t}}\right.$ & 0.2777 & $0.0059^{* * *}$ \\
$\mathrm{D}(\mathrm{LWP})_{\mathbf{t}}$ & -0.0984 & $0.0023^{* * *}$ \\
$\mathrm{D}(\mathrm{LWP}(-1))_{\mathbf{t}}$ & 0.0666 & $0.0615^{*}$ \\
$\mathrm{D}(\mathrm{LWP}(-2))_{\mathbf{t}}$ & 0.0379 & 0.1209 \\
$\mathrm{D}(\mathrm{LWP}(-3))_{\mathbf{t}}$ & 0.1135 & $0.0008^{* *}$ \\
$\mathrm{D}(\mathrm{LRP})_{\mathbf{t}}$ & -0.0310 & 0.1245 \\
$\mathrm{D}(\mathrm{LRP}(-1))_{\mathbf{t}}$ & -0.0506 & $0.0246^{* *}$ \\
$\mathrm{D}(\mathrm{LRP}(-2))_{\mathbf{t}}$ & -0.0162 & 0.3697 \\
$\mathrm{D}(\mathrm{LRP}(-3))_{\mathbf{t}}$ & -0.0586 & $0.0005^{* * *}$ \\
$\mathrm{D}(\mathrm{LBC})_{\mathbf{t}}$ & -0.0595 & $0.0009^{* * *}$ \\
$\mathrm{D}(\mathrm{LBC}(-1))_{\mathbf{t}}$ & -0.1456 & $0.0000^{* * *}$ \\
$\mathrm{D}(\mathrm{LBC}(-2))_{\mathbf{t}}$ & 0.0708 & $0.0150^{* *}$ \\
$\mathrm{D}(\mathrm{LBC}(-3))_{\mathbf{t}}$ & 0.1314 & $0.0000^{* * *}$ \\
$\mathrm{D}(\mathrm{LCC})_{\mathbf{t}}$ & 0.1675 & $0.0002^{* * *}$ \\
$\mathrm{D}(\mathrm{LCC}(-1))_{\mathbf{t}}$ & 0.1449 & $0.0036^{* * *}$ \\
$\mathrm{D}(\mathrm{LGDPP})_{\mathbf{t}}$ & 0.0579 & $0.0003^{* * *}$ \\
$\mathrm{D}\left(\mathrm{LGDPP}(-1)_{\mathbf{t}}\right.$ & 0.5835 & 0.1044 \\
$\mathrm{D}\left(\mathrm{LGDPP}(-2)_{\mathbf{t}}\right.$ & -.3130 & $0.0004^{* * *}$ \\
$\mathrm{D}\left(\mathrm{LGDPP}(-3)_{\mathbf{t}}\right.$ & 0.0478 & $0.0000^{* * *}$ \\
$\mathrm{D}(\mathrm{LPOP})_{\mathbf{t}}$ & 0.0595 & $0.0025^{* * *}$ \\
$\mathrm{D}(\mathrm{LWI})_{\mathbf{t}}$ & 0.1014 & $0.0000^{* * *}$ \\
$\mathrm{D}\left(\mathrm{LWI}(-1)_{\mathbf{t}}\right.$ & -0.1646 & $0.0000^{* * *}$ \\
$\mathrm{D}\left(\mathrm{LWI}(-2)_{\mathbf{t}}\right.$ & -0.0777 & $0.0426^{* *}$ \\
\hline
\end{tabular}

\begin{tabular}{lcc}
\hline $\mathrm{D}(\mathrm{LCPI})_{\mathrm{t}}$ & -0.0345 & $0.0037 * * *$ \\
$\mathrm{ECM}(-1)$ & -1.6452 & $0.0000 * * *$ \\
$*, * *, * * *$ & indicates the 10, 5 and 1 percent \\
significance level, respectively.
\end{tabular}

Source: Authors Calculation

\subsection{Diagnostic Estimates}

The estimated results of the residual diagnostic test had been presented in Table 7. The null hypothesis of the Breusch and Pagan (BP) test is "no heteroskedasticity" in the model. The calculated value of BP statistic is low and insignificant. Therefore, the null hypothesis is accepted, and the estimated model is clear from the heteroskedasticity problem. Similarly, the Breusch and Godfrey (BG) test is adopted to test the autocorrelation problem in the estimated model. The null hypothesis of the BG test is "no autocorrelation", which is accepted as the computed value is lower and insignificant. There is no existence of an autocorrelation problem in the estimated model, and the results are valid for policy implication. The Jarque Bera (JB) test is applied to test the normality of data. The null hypothesis of the JB test is "data is normally distributed", which is accepted as the calculated value is low and insignificant. The structural stability of the estimated model is validated through Cumulative Sum (CUSUM) and Cumulative Sum of Square (CUSUMQ) (see appendix C, Figure 1\&2). The estimated value of CUSUM and CUSUMQ are within 5 percent bounds which shows the cointegration relationship. The diagrams of both the CUSUM and CUSUMQ tests indicate no structural instability in the given model, and parameters show the long-run relationship [47] [48]. The estimated value of diagnostic, stability, and normality tests indicated that the estimated model is good fit and has potential to serve as justifiable policy massages.

Table 7. Residual Diagnostic and Stability Analysis

\begin{tabular}{lll}
\hline $\begin{array}{l}\text { Recommended } \\
\text { Test }\end{array}$ & $\begin{array}{l}\text { Test } \\
\text { statistic }\end{array}$ & Prob. \\
\hline $\begin{array}{l}\text { Heterosckedasticity } \\
\text { Test }\end{array}$ & 0.5549 & 0.9387 \\
$\begin{array}{l}\text { Autocorrelation } \\
\text { LM Test }\end{array}$ & 1.0717 & 0.3613 \\
\hline
\end{tabular}




\begin{tabular}{lll}
\hline Normality Test & 1.8873 & 0.3892 \\
\hline
\end{tabular}

Source: Authors Calculation

Figure 3, shows the actual and forecasted value of wheat consumption, production, population, and the gap in consumption and production in Egypt (see appendix D). The forecasted estimates indicate that wheat consumption and production gap is increasing over time in Egypt, which may cause the food insecurity problems in the future. The food gap identified required to take comprehensive steps to tend the wheat supply and demand in Egypt and feed the growing population. The increasing production and consumption gap puts pressure on wheat imports which cause food insecurity. The wheat consumption in Egypt in 2020 was around 20 million metric tonnes (MT) and increasing at an increasing rate. The forecasted analysis highlights that in 2050 the wheat consumption would be 30 million MT because of population pressure. According to forecasted estimates, Egypt requires about 46 million metric tonnes of wheat to feed around 220 million people in 2100 . The wheat production in 2020 was about 10 million MT, which would reach around 13 million metric tonnes in 2050 and 30 million MT till 2100. On the other hand, the wheat consumption in Egypt for 2020 was about 20 million metric tonnes, and consumption will be 30 million in 2050, and by 2100 the consumption would reach around 46 million MT. Similarly, the Egyptian population is growing at an increasing rate, and during 2020 the population was about 100 million; in 2050, it would be around 140 million, which would be double in 2085, and in 2100 Egyptian population would reach above 220 million. The forecasted estimates highlight that in future the Egyptian economy will face severe food security challenges as the wheat production and consumption gap is increasing over time, as well as population is going to be double in coming 50 years.

\section{Conclusion and Policy Recommendation}

Globally, wheat is a widely consumable staple food and performs an essential role in food security. The purpose of this research is to investigate the determinants of wheat consumption in Egypt, also measured the price, substitution, and income elasticities. For research analysis, this study utilized the annual data covering from 1961 to 2020 . The estimated results of the ARDL test show the existence of a long-run cointegration relationship among estimated variables. The wheat price has a significant and negative impact on wheat consumption, consequently, the law of demand holds in the case of wheat demand in Egypt. The possible justification of the negative impact of wheat price on wheat consumption may be that the people in Egypt are willing to buy more wheat as the wheat price going down. This is called the existence of law of demand in Egyptian wheat consumption and people consume wheat as necessity commodity. The wheat price indicates that wheat is a necessity commodity, and people are willing to buy more wheat at lower prices. Furthermore, the GDP per capita has a significant impact on wheat consumption, which indicates that wheat is a necessity food commodity. Results of GDP per capita highlight that as the per capita income increases the Egyptian people will buy more wheat. This income behavior of wheat commodity fulfils the conditions of economic theory pertaining to necessity commodity. The estimated coefficients of rice prices, corn consumption, and barley consumption performs significant impact on wheat consumption. Therefore, in Egypt, wheat, rice, corn, and barley commodities are consumed as substitutes of wheat with less elastic demand. This indicates that the Egyptian wheat demand is deteriorating comparatively with a decline in rice, barley, and corn prices in Egypt. The Egyptian population is increasing at an increasing rate, and estimated results indicate that the increasing population exerts a positive pressure on wheat consumption. In Egypt, about 50 percent of wheat consumptions are fulfilled through imported wheat and gap between consumption and production is increasing over the time. The analysis results of imported wheat have a significantly positive impact on wheat consumption in Egypt. The results of the consumer price index highlights that an increase in CPI affects the consumer demand for wheat 
negatively. The predicted estimates highlight the food insecurity problems that may arise in Egypt in upcoming decades.

Based on empirical analysis and the estimates, the following policy suggestions are needed to be addressed in order to accomplish the country's demand for wheat:

1. A necessary policy is required for substitutable consumption of wheat regarding rice, corn, and barley.

2. Government should focus on alternative wheat production policies to fulfill the wheat consumption domestically.

3. Egypt government should concentrate on exploring additional water resources for irrigated agriculture and alternative wheat production technology especially use of saline water and biochar soil amendments to offset the salinity effect.

4. In the future, the Egyptian government should manage the annual domestic wheat production above the population growth to maintain or reduce the wheat imports.

5. Government should control the consumer price index; attain higher GDP per capita for wheat consumption accessibility for the low-income group.

6. The appropriate policy is required for wheat imports and wheat production to fill the gap between demand and supply for wheat.

7. Indonesia shifts the consumption pattern from rice to wheat due to high-income growth and urbanization [26]; a similar shift is required in Egypt to change the wheat consumption pattern to other domestically produced substitute commodities (like rice, corn, and barley).

8. It is also suggested that the Egyptian government must focus on pro-poor agriculture growth to meet the wheat demand and alternative staple food.

9. Wheat imports can also be reduced by imposing import tariffs and shifts the population to substitute commodities.

10. It is also suggested that mapping is required to fill the wheat consumption so the ministry of food and agriculture should cope with the increasing wheat consumption.
11. Adopting innovative production techniques with new wheat varieties will be beneficial to enhance wheat production.

\subsection{Future Research Directions}

Research is required on wheat demand, production gap, and alternative shifts at the microlevel. Microlevel research is needed to investigate the wheat production deficiencies and utilize innovative techniques to increase wheat production. Further, a study is needed to find the wheat production patterns and lacking issues in wheat production, through which the Egyptian economy can achieve wheat production self-sufficiency. The study is required in wheat production to utilize the Bio Saline water techniques to increase the land cultivation. Research is also needed on land reclamation and use of bio saline agriculture in Egypt.

\section{References:}

[1] Barnes, J. N., \& Shields, D. A. (1998). The growth in US wheat food demand. Wheat Yearbook, 21-29.

[2] Mason, N. M., Jayne, T., \& Shiferaw, B. (2015). Africa's rising demand for wheat: Trends, drivers, and policy implications. Development Policy Review, 33(5), 581-613.

[3] Mottaleb, K. A., Kruseman, G., \& Erenstein, O. (2018). Wheat production and consumption dynamics in an Asian rice economy: The Bangladesh case. The European Journal of Development Research, 30(2), 252-275.

[4] Timsina, J., Wolf, J., Guilpart, N., Van Bussel, L. G. J., Grassini, P., Van Wart, J., .. \& Van Ittersum, M. K. (2018). Can Bangladesh produce enough cereals to meet future demand?. Agricultural systems, 163, 36-44.

[5] Veninga, W., \& Ihle, R. (2018). Import vulnerability in the Middle East: effects of the Arab spring on Egyptian wheat trade. Food Security, 10(1), 183-194.

[6] Kassim, Y., Mahmoud, M., Kurdi, S., \& Breisinger, C. (2018). An agricultural 
policy review of Egypt: First steps towards a new strategy.

[7] Khodeir, M. H., \& Abdel-salam, H. (2015). A simulation model for wheat-related policies and food insecurity in Egypt. Paper presented at the System Dynamics Conference.

[8] Tanaka, T. (2018). Agricultural selfsufficiency and market stability: a revenueneutral approach to wheat sector in Egypt. Food Secur, 6, 31-41.

[9] Abdalla, M., \& Al-Shawarby, S. (2017). The Tamween food subsidy system in Egypt: Evolution and recent implementation reforms.

[10] Ramadan, R., \& Thomas, A. (2011). Evaluating the impact of reforming the food subsidy program in Egypt: a mixed demand approach. Food Policy, 36(5), 638646.

[11] Rohac, D. (2013). Solving Egypt's Subsidy Problem. Policy Analysis(741).

[12] FAO (2016) Food Outlook Biannual Report on Global Food Markets, Available at http://www.fao.org/3/i6198e/i6198e.pdf

[13] Asseng, S., Kheir, A. M., Kassie, B. T., Hoogenboom, G., Abdelaal, A. I., Haman, D. Z., \& Ruane, A. C. (2018). Can Egypt become self-sufficient in wheat? Environmental Research Letters, 13(9), 094012.

[14] USDA (2021). United State Department of Agriculture, Foreign Agriculture Services, 2021, the report is available at: https://www.fas.usda.gov/data/egypt-grainand-feed-annual-5

[15] World Population Review (2021) available at https://worldpopulationreview.com/ countries/Egypt-population.

[16] Abdelmageed, K., Chang, X. H., Wang, D. M., Wang, Y. J., Yang, Y. S., Zhao, G. C., \& Tao, Z. Q. (2019). Evolution of varieties and development of production technology in Egypt wheat: A review. Journal of integrative agriculture, 18(3), 483-495.

[17] FAO (2020). Food and agriculture Organization, 2020. Available at Http://Www.Fao.Org/CountryShowcase/Item-Detail/En/C/1287824/

[18] Yijie, W., Ling, X., Zhiquan, H., \& Xiaoning, A. (2018). Current Sittuation of
Production, Consumption and Trade of Wheat in China. Chinese Journal of Agricultural Resources and Regional Planning, 05.

[19] Kherallah, M., Minot, N., \& Gruhn, P. (2003). Adjustment of wheat production to market reform in Egypt. In Food, Agriculture, and Economic Policy in the Middle East and North Africa: Emerald Group Publishing Limited.

[20] Mansour, H., Abd El-Hady, M., Bralts, V., \& Engel, B. (2016). Performance automation controller of drip irrigation systems using saline water for wheat yield and water productivity in Egypt. Journal of Irrigation and Drainage Engineering, 142(10), 05016005.

[21] Solieman, N. Y., Barghash, R. M., \& Hassan, A. A. (2015). Economic study of the impact of using some technological methods on Egyptian wheat crop productivity. Life Science Journal, 12(1), 12-20.

[22] Patni, N., Pillai, S. G., \& Dwivedi, A. H. (2013). Wheat as a promising substitute of corn for bioethanol production. Procedia Engineering, 51, 355-362.

[23] Mosinmileoluwa A., Ochei A. I., Godswill O. O., Grace E. (2021) Impact of Agricultural Credit on Economic Growth in Nigeria. WSEAS Transactions on Business and Economics, 18(52), 511-523.

[24] Usman, M. ., Hameed, G., Saboor, A. \& Saddozai, K. N. (2020). Technological Spillovers, Manufacturing Growth and Transboundary Pollution in Case of Pakistan. Journal of Applied Economics and Business Studies, 4(2), 23-40.

[25] Terry, J. J., \& Marsh, T. L. (2000). Derived demand for wheat by class. Retrieved from

[26] Fabiosa, J. F. (2006). Westernization of the Asian diet: the case of rising wheat consumption in Indonesia.

[27] Haral, M. A., \& Yasin, M. (2019). Determinants of Speculative Demand of Wheat and Its Impact on Consumer Welfare Loss. Journal of Economic Impact, 1(3), 87-91.

[28] Mukhtar, T., \& Ilyas, M. (2009). Cointegration and Error-Correction Modelling of Wheat Consumption in 
Pakistan. Journal of Economic Cooperation \& Development, 30(4).

[29] Zulfiqar, M., \& Chishti, A. (2010). Development of supply and demand functions of pakistan's wheat crop. The Lahore Journal of Economics, 15(1), 91102.

[30] Uhl, K. M., Perekhozhuk, O., \& Glauben, T. (2018). Russian market power in international wheat exports: Evidence from a residual demand elasticity analysis. Journal of Agricultural \& Food Industrial Organization, 17(2).

[31] Han, J., \& Jeong, H. (2010). Factors expanding consumption of domestic wheat processed products. Korean Journal of Agricultural Management and Policy.

[32] Matin, M., \& Alam, S. (2004). Demand, supply estimation and projection of wheat situation in Bangladesh. Bangladesh Journal of Agricultural Economics, 27(454-2016-36662), 25-44.

[33] Meyer, F., \& Kirsten, J. (2005). Modelling the wheat sector in South Africa. Agrekon, 44(2), 225-237.

[34] Alamri, Y., \& Al-Duwais, A. (2019). Food Security in Saudi Arabia (Case Study: Wheat, Barley, and Poultry). Yosef Alamri, and Abdulaziz Al-Duwais, "Food Security in Saudi Arabia (Case Study: Wheat, Barley, and Poultry)." Journal of Food Security, 7(2), 36-39.

[35] Baiyegunhi, L., \& Sikhosana, A. (2012). An estimation of import demand function for wheat in South Africa: 1971-2007. African Journal of Agricultural Research, 7(37), 5175-5180.

[36] Lampietti, J. A., Michaels, S., Magnan, N., McCalla, A. F., Saade, M., \& Khouri, N. (2011). A strategic framework for improving food security in Arab countries. Food Security, 3(1), 7-22.

[37] Negeri, A., \& Quan, J. (2020). Determinants of Wheat Market Outlet Choice of Cooperative Members: The Case of Hetosa District, Ethiopia. Marketing, $6(1)$.

[38] Uzunoz, M., \& Akcay, Y. (2009). Factors affecting the import demand of wheat in Turkey. Bulgarian J. Agri. Sci, 15, 60-66.
[39] Pesaran, M. H., Shin, Y., \& Smith, R. J. (2001). Bounds testing approaches to the analysis of level relationships. Journal of applied econometrics, 16(3), 289-326.

[40] Abdulhafedh, A. (2017). How to detect and remove temporal autocorrelation in vehicular crash data. Journal of transportation technologies, 7(2), 133-147.

[41] Usman, M. (2016). Growth Effects of Fiscal and Monetary Policies in Pakistan. The Pakistan Development Review, 529552.

[42] Yazdanshenas, L., Moghadasi, R., \& Yazdani, S. (2012). A Model for the Wheat Market in Iran. International Journal of Agricultural Science and Research, 2(2), 49-55.

[43] Aslam, M. (2009). Food autarky through substitution between rice and wheat: An econometric analysis. Pakistan Journal of Agricultural Research (Pakistan).

[44] Oladunmoye, O., Akinoso, R., \& Olapade, A. (2010). Evaluation of some physicalchemical properties of wheat, cassava, maize and cowpea flours for bread making. Journal of Food Quality, 33(6), 693-708.

[45] Dibaba, R. (2019). Wheat Production, Marketing and Consumption in Ethiopia

[46] Azeem, M. M., Munawwar, S., \& Mushtaq, K. (2012). An empirical analysis of factors affecting food (wheat) inflation in Pakistan. Pak. J. Agri. Sci, 49(2), 199-203.

[47] Chandio, A. A., Jiang, Y., \& Rehman, A. (2019). Using the ARDL-ECM approach to investigate the nexus between support price and wheat production. Journal of Asian Business and Economic Studies.

[48] Koondhar, Mansoor Ahmed, Houjian Li, Huiling Wang, Sanchir Bold, and Rong Kong. "Looking back over the past two decades on the nexus between air pollution, energy consumption, and agricultural productivity in China: a qualitative analysis based on the ARDL bounds testing model." Environmental Science and Pollution Research (2020): 1-15. 


\section{Contribution of individual authors to the creation of a scientific article (ghostwriting policy)}

Author Contributions:

Both authors have equally contributed towards data collection and writing of this manuscript. Lal Almas contributed towards abstract, introduction, conclusion \& policy recommendations and other technical aspects. Muhammad Usman have carried out statistical analysis and contributed towards research methodology, model development, results/discussion and bibliography.

\section{Sources of funding for research presented in a scientific article or scientific article itself}

The research in this manuscript has been partially supported by the Binational Fulbright Commission in Egypt (BFCE) under Fulbright Alumni Activity: Egypt Food Security Research Project (EFSP) grant, 2019-2021. Visiting Research Fellow from Pakistan has been funded by Punjab Higher Education Commission (PHEC), Pakistan through his institution,

PMAS- Arid Agriculture University, Rawalpindi, Pakistan.

\section{Creative Commons Attribution}

\section{License 4.0 (Attribution 4.0}

\section{International, CC BY 4.0)}

This article is published under the terms of the Creative Commons Attribution License 4.0 https://creativecommons.org/licenses/by/4.0/dee d.en US 


\section{Appendixes}

A)

Table 3: Lag length Criterions

\begin{tabular}{llll}
\hline Lag & AIC & SC & HQ \\
0 & -5.936 & -5.610 & -5.810 \\
1 & -22.352 & $-19.097 *$ & -21.090 \\
2 & -22.429 & -16.244 & -20.031 \\
3 & -22.304 & -13.190 & -18.771 \\
4 & $-26.908^{*}$ & -14.864 & $-22.239 *$ \\
\hline
\end{tabular}

Source: Authors Calculation
B)

Table 4: Bounds Test

\begin{tabular}{lll}
\hline & Value & $\mathrm{K}$ \\
\hline $\begin{array}{l}\text { Calculated F- } \\
\text { statistic }\end{array}$ & 10.64563 & 8 \\
Critical Value & & \\
level of & Lower- & Upper- \\
Significance & Bound & Bound \\
$2.5 \%$ & 2.82 & 4.02 \\
$1 \%$ & 3.15 & 4.43 \\
\hline Source: & Authors & \multicolumn{1}{c}{ Calculation }
\end{tabular}

C)

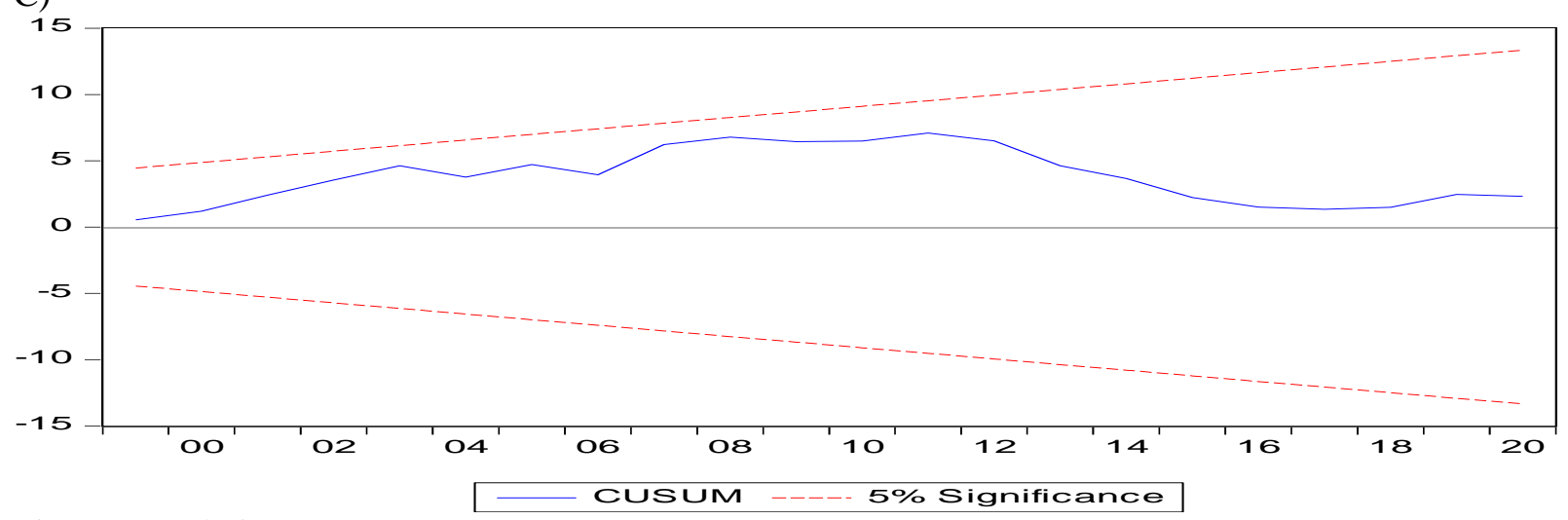

Fig. 1 Cumulative Sum

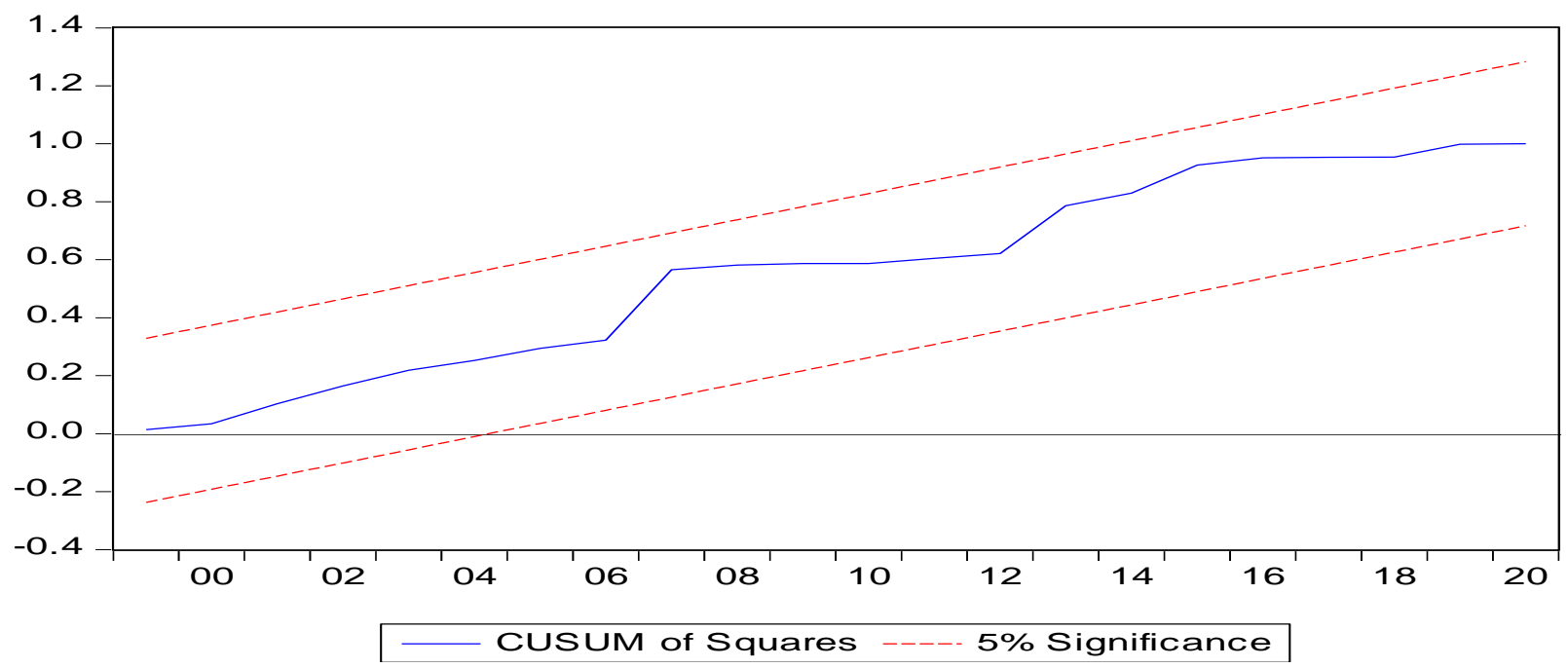

Fig. 2 Cumulative Sum of Square 
D)

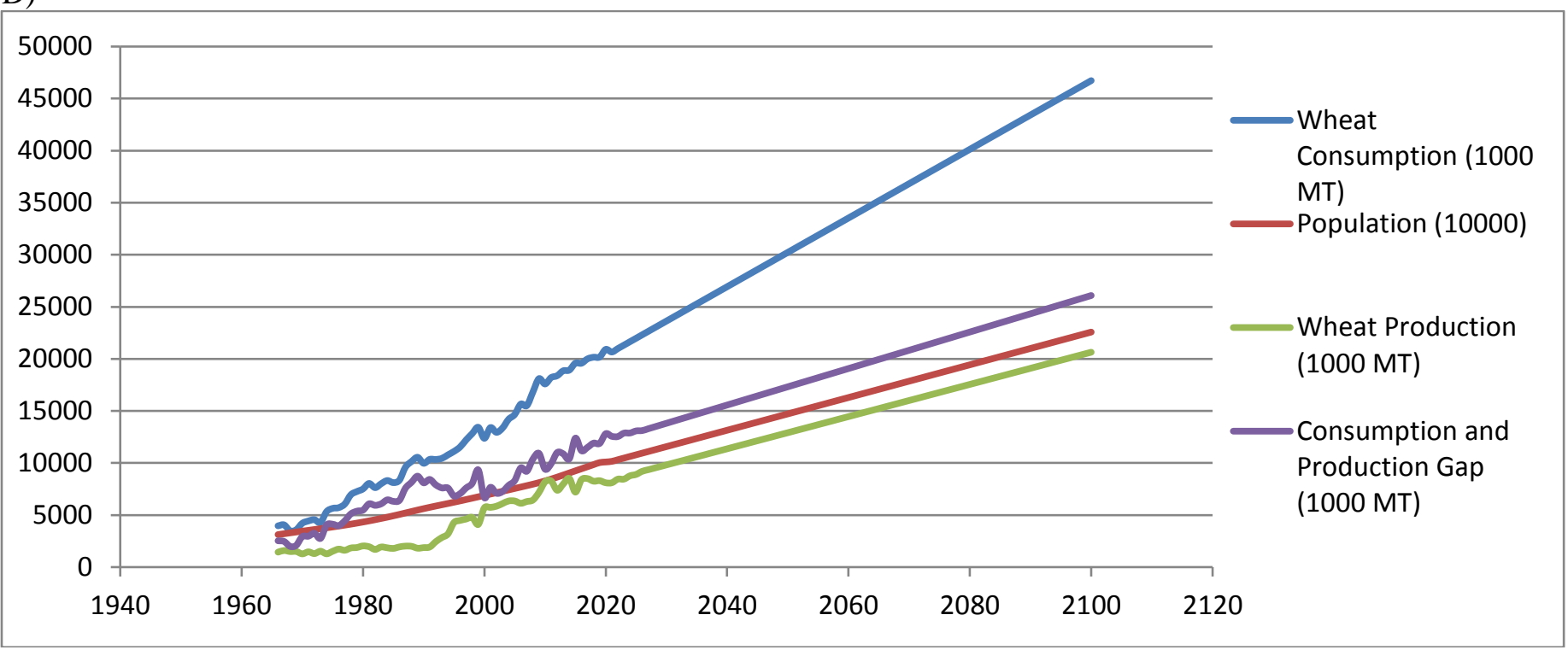

Fig. 3 Demand for Wheat with Growing Population in Egypt

Source: Authors Analysis 